
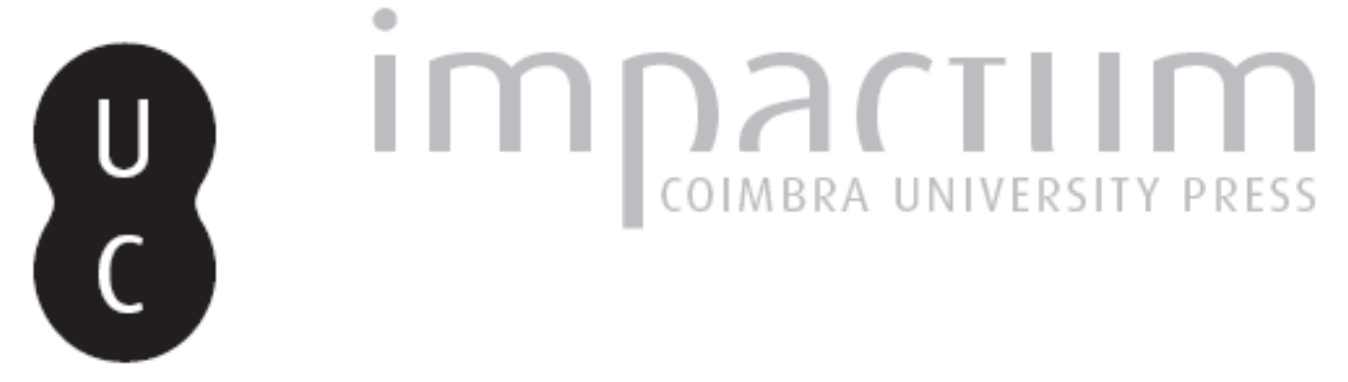

\title{
Novas responsabilidades do jornalismo face à liquidificação da profissão: fundamentos normativos, valores, formação
}
Autor(es):
Camponez, Carlos

Publicado por: Imprensa da Universidade de Coimbra

URL

persistente:

URI:http://hdl.handle.net/10316.2/43894

DOI:

DOI:https://doi.org/10.14195/2183-5462_32_2

Accessed : $\quad$ 26-Apr-2023 15:41:01

A navegação consulta e descarregamento dos títulos inseridos nas Bibliotecas Digitais UC Digitalis, UC Pombalina e UC Impactum, pressupõem a aceitação plena e sem reservas dos Termos e Condições de Uso destas Bibliotecas Digitais, disponíveis em https://digitalis.uc.pt/pt-pt/termos.

Conforme exposto nos referidos Termos e Condições de Uso, o descarregamento de títulos de acesso restrito requer uma licença válida de autorização devendo o utilizador aceder ao(s) documento(s) a partir de um endereço de IP da instituição detentora da supramencionada licença.

Ao utilizador é apenas permitido o descarregamento para uso pessoal, pelo que o emprego do(s) título(s) descarregado(s) para outro fim, designadamente comercial, carece de autorização do respetivo autor ou editor da obra.

Na medida em que todas as obras da UC Digitalis se encontram protegidas pelo Código do Direito de Autor e Direitos Conexos e demais legislação aplicável, toda a cópia, parcial ou total, deste documento, nos casos em que é legalmente admitida, deverá conter ou fazer-se acompanhar por este aviso.

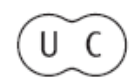




\section{Mediasornalismo}

ÉTICA JORNALÍSTICA PARA O SÉCULO XXI NOVOS DESAFIOS, VELHOS PROBLEMAS

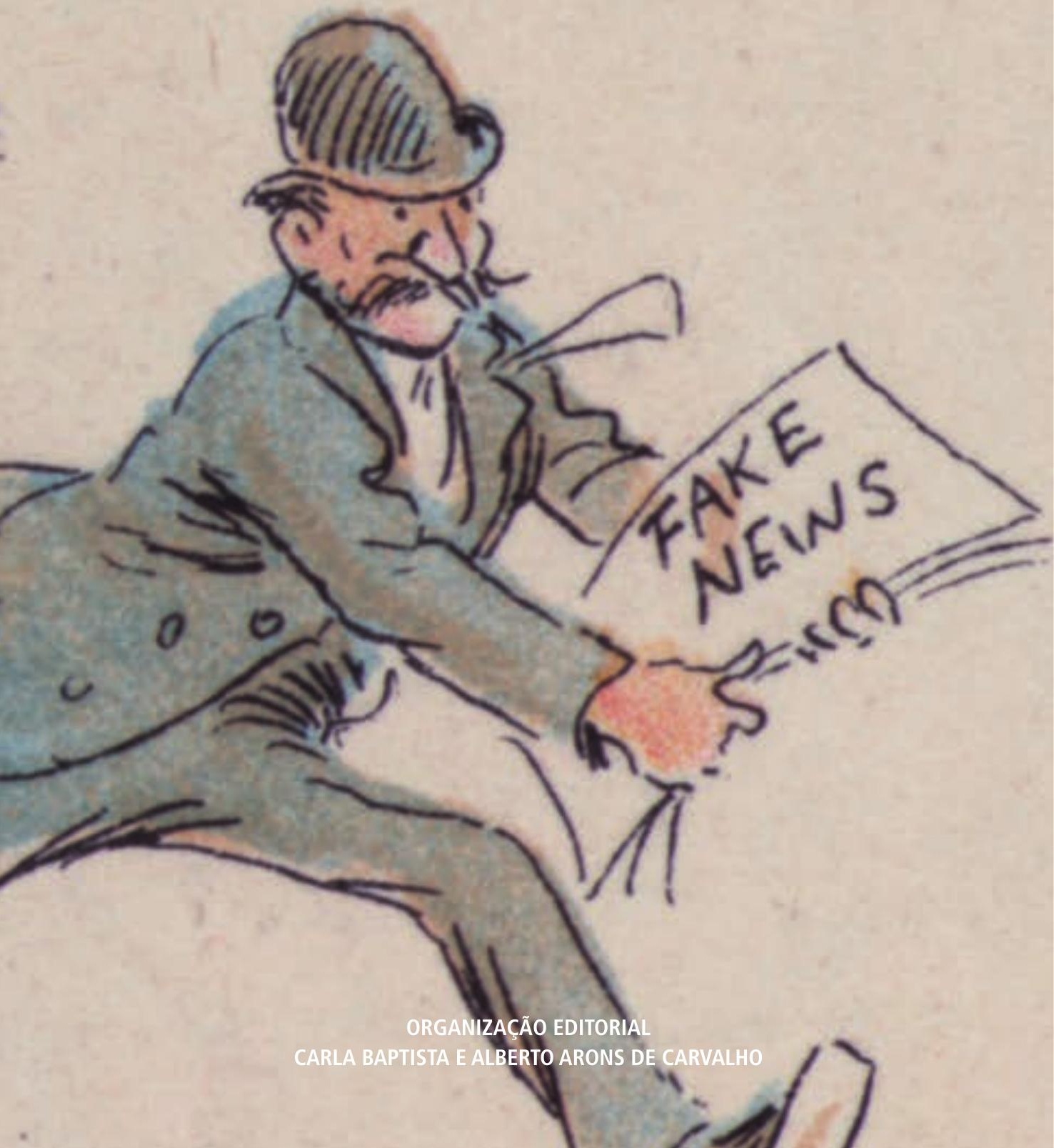




\title{
NOVAS RESPONSABILIDADES DO JORNALISMO FACE À LIQUIDIFICAÇÃO DA PROFISSÃO - FUNDAMENTOS NORMATIVOS, VALORES, FORMAÇÃO
}

\author{
THE NEW RESPONSABILITIES OF JOURNALISM IN THE FACE OF THE \\ LIQUEFYING OF THE PROFESSION - NORMS, VALUES, TRAINING
}

NueVAS RESPONSABILIDAdES DEL PERIOdISMO FRENTE A LA LIQUIDACIÓN DE LA PROFESIÓN - FUNDAMENTOS NORMATIVOS, VALORES Y FORMACIÓN

\section{Carlos Camponez}

Universidade de Coimbra, Faculdade de Letras. Departamento de Filosofia,

Comunicação e Informação. 3004-530 Coimbra, Portugal

carlos.camponez@fl.uc.pt

Artigo por convite/Article by invitation/ Artículo por invitación

\section{Resumo}

0 impacte das tecnologias no ecossistema mediático alterou alguns axiomas sobre o papel do jornalismo nas democracias contemporâneas e está a promover a diluição e a banalização da profissão. Essas alterações colocam o jornalismo perante a responsabilidade ética de se refundar, reforçando os seus laços com a democracia num mundo crescentemente global, definindo o núcleo de saberes mínimos e dos percursos formativos exigíveis e adotando modelos organizativos e de representação profissional consonantes com as suas novas responsabilidades sociais.

\section{Palavras-chave}

Liberdade de expressão; desprofissionalização do jornalismo; ensino do jornalismo; "jornalismo orientado para a democracia"

\section{ABstract}

The impact of new technologies observed in the media ecosystem have altered some axioms about the role of journalism in contemporary democracies and are promoting the dilution and banalization of the profession. These changes place journalism under the ethical responsibility of re-founding itself in order to continue playing its social role in an increasingly global world. This task comprises strengthening its ties with democracy, defining a core of minimum knowledge and corresponding training paths, as well as adopting organizational and professional representation models in line with its new social responsibilities.

\section{KEYWORDS}

Freedom of speech; de-professionalization of journalism; journalism training; "democracy-driven journalism" 


\section{Resumen}

El impacto de las tecnologías en el ecosistema mediático alteró algunos axiomas sobre el papel del periodismo en las democracias contemporáneas y está promoviendo la dilución y la banalización de la profesión. Estos cambios colocan al periodismo ante la responsabilidad ética de refundarse, reforzando sus lazos con la democracia en un mundo crecientemente global, definiendo el núcleo de saberes mínimos, los itinerarios formativos exigibles y adoptando modelos organizativos y de representación profesional en consonancia con sus nuevas responsabilidades sociales.

\section{Palabras clave}

Libertad de expresión; desprofesionalización del periodismo; enseñanza del periodismo; "Periodismo orientado hacia la democracia"

\section{INTRODUÇÃO}

A discussão em torno do acesso à profissão e da importância das organizações socioprofissionais no jornalismo, na era da sua desprofissionalização, evoca o "canto do cisne". A literatura é unânime em estabelecer uma ligação entre o exercício de uma profissão e os seus valores éticos. Neste contexto, será legítimo perguntar até que ponto poderá o jornalismo responder perante as suas responsabilidades sociais, num quadro geral marcado por uma "liquidificação" da profissão? Defenderemos a necessidade de se proceder ao fechamento da profissão e ao reforço das suas estruturas representativas e de accountability. Não entendemos esse processo numa perspectiva corporativa, mas como uma forma de responder às transformações verificadas no campo dos media, alterando os pressupostos que justificaram, durante cerca de século e meio de jornalismo profissional, que o jornalismo se mantivesse como uma profissão aberta.

\section{Problematização}

Duas questões inspiram a reflexão que se segue. A primeira tem a ver com a imbricação entre as organizações socioprofissionais e a emergência dos valores éticos no domínio económico e profissional, no sentido em que escrevia Durkheim (1940: 24):

"Para que uma moral e um direito profissionais se possam estabelecer nas diferentes profissões económicas, é necessário que a corporação, em vez de permanecer um agregado confuso e sem unidade, se torne, ou antes, volte a ser um grupo definido, numa palavra, uma instituição pública" (Durkheim, 1940, p. 24).

Ruellan, partindo da análise dos discursos fundadores do jornalismo em França, argumenta, ao contrário de Durkheim, que é antes o facto de os indivíduos "que não estão organizados e não têm um sentimento de grupo, mas que partilham já valores, visões, modalidades sociais, dito de outro modo uma moral", que faz emergir 
entidades coletivas. Porém, esta abordagem não exclui o essencial do nosso argumento de partida acerca das "organizações de jornalistas como focos de emergência de discursos" (Ruellan, 2010, pp. 5-6), estruturantes da ética e das identidades profissionais e, por conseguinte, das suas responsabilidades sociais.

A segunda questão é também uma perplexidade: perante a necessidade de compaginar os valores éticos do jornalismo com as mudanças em curso (Bastos, 2001; McBride \& Rosentiel, 2014; Ward, 2013), como, será possível ou viável pensar-se na possibilidade de tal tarefa num contexto socioprofissional marcado por um processo global de desprofissionalização (Sennett, 2006), "dissolução" (Cornu \& Ruellan, 1993, p. 156) e de liquidificação do Jornalismo (Deuze, 2005, p. 450)?

Em consonância com os pressupostos teóricos anteriores, é de admitir que estes processos gerarão novas identidades, novos valores, em suma, um novo êthos, no sentido aristotélico do termo. Mas será ele compaginável com os valores da credibilidade, da independência e da verdade ao serviço de uma informação pública de qualidade e ao serviço da democracia? Ou será apenas um êthos orientado para o mercado (Edström, Kenyon \& Svensson, 2016)? As exigências deontológicas de autorregulação dos jornalistas feitas por documentos éticos de referência' não se compaginam com a indiferença perante o processo de dissolução da profissão em curso. Antes, fazem apelo a um maior fechamento da profissão, distinguindo as especificidades e responsabilidades próprias do jornalismo face a outras formas de comunicação pública.

A discussão do jornalismo como profissão e a justificação do não fechamento das suas fronteiras estão suportadas numa vasta literatura que salienta a inexistência de um corpo de saber suficientemente coeso, que configure um saber próprio e acessível através de uma formação superior (Lambeth, 1992, Solosky, 1993, Splichal \& Sparks, 1994). Dois outros argumentos parecem-nos relevantes nesta discussão: 0 de 0 acesso aberto à profissão obedecer a uma questão estratégica destinada a responder a particularidades resultantes de uma profissão em transformação permanente (Ruellan, 1997) com novas funções e novos saberes; e - talvez o mais importante de todos os argumentos - a sensibilidade do fechamento de uma profissão com profundas ligações à liberdade de expressão e livre circulação de ideias, (Giroux, 1991, Mesquita 2003; Camponez, 2011).

Sustentaremos que a alteração do ecossistema dos media tornou necessária a criação de condições de acesso à profissão mais exigentes. Com efeito, as Novas Tecnologias da Informação e da Comunicação (NTIC) e o multimédia em linha introduziram um conjunto de mudanças que, do ponto de vista normativo, o jornalismo ainda não assimilou completamente, mas que têm implicações nas condições de exercício da liberdade de expressão e de imprensa, nas competências técnicas e formativas exigíveis aos jornalistas e nas expectativas sociais de uma profissão como o jornalismo.

1 Veja-se, a este propósito, a Declaração de Chapultepec, da Sociedade Interamericana de Imprensa; a Declaração de Princípios de Conduta dos Jornalistas, da Federação Internacional de Jornalistas; a Declaração de Princípios do Jornalismo Centro-Americano, do Centro Latino-Americano de Jornalismo (CELAP); ou a resolução 1003 da Assembleia Geral do Conselho da Europa. 


\section{NoVOS DESAFIOS À LIBERDADE DO JORNALISMO}

A liberdade de expressão e a liberdade de imprimir ${ }^{2}$ estão ligadas ontológica e epistemologicamente, não podendo, por isso, dissociar-se sem se comprometerem mutuamente. Embora a liberdade de expressão e de imprimir tivesse, nos autores liberais clássicos, por principal preocupação o livro, qualquer história dos media e do jornalismo mostra quão importante foi o papel dos jornais na expressão e salvaguarda dessa liberdade (Eveno, 2010) e na emergência do próprio conceito de opinião pública (Habermas, [1962] 2013).

Porém, o jornalismo, enquanto profissão, foi-se construindo em torno de objetivos de uma nova função social, atribuída a um corpo específico de profissionais, cada vez menos entendidos como opinadores, detentores de uma liberdade de dizer, mas a quem se reconhecem deveres, num quadro de uma liberdade para ${ }^{3}$ melhor realizar objetivos sociais, cada vez mais conformados com a ideia de um serviço público de informação e com o valor da democracia.

Se começaram por surgir como uma "liberdade para expressar ideais políticos" (Bulmer \& Bell, 1985, p. 20), a liberdade de expressão e a liberdade de imprensa justificam-se como forma de limitar o poder do Estado e da Igreja (Montalbán, 1997) sobre a verdade e de vigiar os governos (Splichal, 2002), mas, de uma forma mais moderna, também pela incerteza epistemológica que invadiu as esperanças de uma objetividade jornalística, em resultado da crítica a que o conceito foi, justamente, submetido, durante todo o século XX (Mesquita, 2003, Ward, 2004, Shudson, 2010). Com efeito, de forma reforçada pela natureza própria da sua temporalidade e das suas condições de produção, a objetividade e a verdade em jornalismo são conceitos e realidades dialógicos, no sentido iluminista e liberal em que a verdade e 0 erro são realidades inextrincáveis de uma mesma narrativa, não podendo ser dirimíveis pelo fogo e pela espada, mas só alcançáveis pela discussão crítica e livre. Deste modo, à expressão bíblica segundo a qual $A$ Verdade nos libertará (João, 8:32), o pensamento liberal acrescentou a ideia de que, - se não existe liberdade sem verdade, - também não existe verdade sem liberdade, submetendo, deste modo, o valor normativo da verdade ao dialogismo crítico e à crítica escrutinadora dos poderes instituídos, conceitos igualmente centrais na ideologia do jornalismo.

A liberdade de expressão e de imprensa representa também a oportunidade de inscrição na agenda pública de temas considerados relevantes para debate, seguindo o princípio de que os media não nos dizem apenas como pensar, mas também sobre o que pensar (Cohen citado por Wolf, 1987, p. 128). Esta dimensão é tanto mais importante - diremos até, sensível - quanto maior for a centralidade dos media e do jornalismo na mediação e na determinação dos temas públicos em discussão. Neste contexto, a perspetiva da liberdade de expressão e de imprimir como liberdade subjetiva e como liberdade editorial de inscrever no quotidiano dos cidadãos novos temas, não pode ser negligenciada no jornalismo. No entanto, se o jornalismo, até

2 Liberdade de imprimir ou - numa expressão mais adequado aos dias de hoje - liberdade de transmitir e de difundir as suas ideias.

3 A distinção entre liberdade de e liberdade para é usada por Isaiah Berlin para distinguir as noções de liberdade positiva (não condicionada, na linha do que define a Primeira Emenda) e uma liberdade positiva, normalmente subjugada a objetivos sociais específicos. 
um passado relativamente recente, se realizou num contexto de limitação de acesso aos media e de escassez de informação, nunca como hoje, na nova Cosmopolis (Ash, 2017), as sociedades e os indivíduos tiveram tantos meios para comunicarem o seu pensamento. A internet ocupou normativamente o lugar da liberdade de imprimir e de difundir, transformando-se numa plataforma privilegiada de transmissão e difusão de mensagens e de ideias, de forma pouco onerosa e sem a necessidade tradicional da intermediação, quer dos media quer dos jornalistas (Dourado, 2009: 4). Este ambiente define o que Castells $(2009$, p. 55) denominou por comunicação individual de massas, caracterizada por um modelo em que muitos comunicam para muitos (Castells, 2008, p. 90), onde as pessoas "enviam mais do que recebem, em que filtrar, ponderar e eliminar comunicações se afigura essencial para sobreviver à superabundância informativa" (Deuze 2017, p. 12).

A convergência tecnológica permitiu também o reforço das grandes corporações de media, chamando a atenção para a necessidade de o poder escrutinador não se dever limitar ao Estado mas às próprias condições do mercado dos media e aos efeitos que o "medium dinheiro vem assumindo sobre o poder político" (Pissarra, 2015, p. 129), os valores jornalísticos e a mercadorização dos conteúdos informativos e dos públicos. Estas críticas põem em causa um conjunto de axiomas acerca do papel tradicional dos media nas sociedades contemporâneas (Ulla, 2016, p. 22), tornando pertinente distinguir entre uma liberdade de expressão (empresarial) orientada para o mercado e a liberdade de expressão orientada para a democracia (Kenyon, 2016, pp. 29-39).

Novas condições de comunicação pública implicam novas formas de pensar 0 jornalismo. A democratização da liberdade de expressão e a facilidade de acesso aos media e à difusão de ideias, colocam definitivamente o jornalismo no campo de uma liberdade positiva "que não se limita a recusar a censura política, ou qualquer outro tipo de censura, mas como a afirmação de uma tarefa a preencher: satisfazer o direito à informação de cada cidadão" (Bertrand, 1997, p. 34) e servir a democracia (Ulla, 2016, p. 22).

\section{JORNALISMO E SERVIÇO PÚBLICO}

0 jornalismo profissional e a reivindicação da sua autonomia fizeram-se, do ponto de vista ideológico e normativo, em nome do serviço público (Shudson, 2010; Kovac e Rosenstiel, 2005; Deuze, 2005, Garcia \& Meireles, 2017). Walter Williams, fundador da primeira escola de jornalismo no mundo, nos EUA, em 1908, considerou no seu Journalist's Creed que o jornalismo tinha como objetivo último o serviço público que "a aceitação de um serviço menor do que o serviço público é uma traição a essa missão". Os Princípios Internacionais da Ética Profissional no Jornalismo, da Unesco (1983), referem que a informação é entendida como bem social e não como mercadoria, o que implica que o jornalista compartilhe a responsabilidade não apenas para com as empresas mas também para com o público. A ideia de serviço público é também transversal à própria existência dos media (Bertrand, 1997, p. 26), assim como está implícita no compromisso de limitação dos poderes atribuídos aos jornalistas e aos media através da autorregulação (Powell \& Jempson, 2014).

0 crescente processo de desintermediação que as NTIC têm vindo a promover nas sociedades contemporâneas, reforçam as responsabilidades dos jornalistas na 
garantia deste serviço público, abrindo a discussão sobre a função social do jornalismo (Deuze, 2017) e, inclusivamente, sobre a necessidade de refundação dos seus valores éticos, com base em novos pressupostos (Ward, 2012 e 2015).

0 aparecimento de novos atores sociais e organizações a disputarem algumas das tarefas dos jornalistas (Dahlgren, 2012, pp. 179-180; Mesquita 2002) complexificou e tornou mais exigentes as formas de o jornalismo exercer as suas funções normativas, no que se refere ao serviço público, à objetividade, ao tratamento da atualidade e, naturalmente, aos seus compromissos éticos (Deuze, 2005). 0 jornalismo não só deixou de ser o único meio de expressão, transmissão e difusão de opiniões, como os cidadãos adquiriram a capacidade de "cometer atos de jornalismo" (Stearns, 2013).

As NTIC trouxeram possibilidades incontestáveis de participação dos cidadãos na vida pública e política (Fenton, 2012; Dahlgren, 2014), mas isso não significa que percamos o sentido crítico acerca das suas possibilidades de realização. Com efeito, as esperanças excessivas no potencial emancipador das "Novas" TIC não é apenas um erro do presente (Kumar, 1995, pp. 23 e ss) e, no caso da internet, de uma forma geral, esse potencial «tem sido, na melhor das hipóteses, lento na sua concretização" (Ferreira, 2011. p. 59). Esses erros de avaliação são recorrentes porque frequentemente se esquece que as NTIC não existem per se mas surgem em contextos sociais humanos que determinaram os seus usos. Por outro lado, as NTIC introduziram também novos problemas na esfera pública contemporânea, de que as discussões sobre as câmaras de eco (Keane, 2013: 123), a proliferação de notícias falsas (Allcott \& Gentzkow, 2017), a fragmentação dos públicos - mais benéficos à criação de nichos de mercado do que a uma opinião pública deliberativa - ou os efeitos do "pensamento de colmeia" (Keane, 2013: pp. 122 e 123), são apenas alguns exemplos.

Nem tão-pouco as NTIC inauguraram o renascimento do jornalismo. Antes pelo contrário, favoreceram o reforço das grandes marcas e induziram um declínio da qualidade da informação, não compensado pelas novas formas de jornalismo (Curran, des Freedman \& Fenton, 2012, p. 179).

Neste contexto, é natural que as reflexões sobre o jornalismo na era da abundância da comunicação explorem o contributo do jornalismo no combate aos efeitos sociais perversos resultantes do uso das NTIC e insistam no seu papel no quadro da realização dos objetivos da democracia, num mundo global (Keane 2013; Ward 2013).

Nesta linha de pensamento, Edwy Plenel, ex-jornalista do jornal francês Le Monde (1980-2004) e fundador da Mediapart, em 2008, refere-se ao jornalismo como uma profissão que se define pelo facto de estar "na primeira linha de um direito essencial em democracia, o direito à informação, o direito de saber". Daí decorre, segundo Plenel, a razão de se pensar a profissão de uma forma exigente, uma vez que a liberdade reivindicada pelos jornalistas é uma liberdade que deverá estar ao "serviço dos concidadãos e de um ideal que nos ultrapassa, a democracia" (July, Kahn \& Plenel, 2009, pp. 121-122):

"Estamos a viver o advento do medium pessoal, individual, participativo: para se exprimirem no espaço público, os cidadãos não precisam de nós. Alguns jornalistas estão inquietos por isso. Eu, pelo contrário, vejo nisso uma boa novidade: desviando o jornalista do comentário, é o convite para nos virarmos para o essencial da profissão - a informação, o inquérito, o terreno" (July et al, 2009, p. 115-116) 


\section{Desafios formativos}

As novas responsabilidades para com a qualidade da informação implicam um novo olhar sobre a formação do jornalismo, enquanto lugar privilegiado de transmissão de saberes e de valores. Porém, ainda que cada vez menos se questione a relevância de uma formação superior dos jornalistas, o mesmo já não se poderá dizer sobre a necessidade dessa formação ser, especificamente, em jornalismo (Coelho 2014; Delporte, 2015; Mesquita, 2012), ao ponto de, por vezes, ela ficar confinada a uma aprendizagem técnica, pós-graduada (Peixinho 2016, p. 108).

Mike Ward, ex-jornalista da BBC, por exemplo, olha o jornalista na sua dimensão quase vocacional de criatividade, de sensibilidade e de agilidade, ao mesmo tempo que considera que os seus princípios fundamentais e técnicas básicas estão ao alcance da maioria das pessoas.

"Ainda que possam ser uma espécie de escritores, não têm os direitos de um nobre. 0 quarto poder não é uma monarquia; é uma república. No Online, há o potencial de incluir os milhões que estão pesquisando e publicando na web a cada dia" (Ward, 2007 p. 31).

Por seu lado, Christian Delporte, embora reconheça que não seja por esse caminho que os ditames do mercado profissional estejam a evoluir, salienta que o futuro dos cursos de jornalismo depende da sua capacidade de desenvolver o espírito crítico, em detrimento de meros mecânicos do pensamento, acentuando o sentido do termo complexidade, de que falámos atrás, embora mantendo-a no quadro de uma profissão aberta, não condicionada à exigência de obtenção de um diploma especializado em jornalismo (Delporte 2016, pp. 21-22).

Na mesma linha de pensamento, Mário Mesquita considera que, sendo desejável que se solicite ao jornalista uma formação universitária, não será conveniente condicionar o seu acesso aos detentores de determinado título académico, salientando que "as tentações corporativistas serão sempre prejudiciais à liberdade de expressão" (Mesquita, 2002, p. 192).

A defesa de uma formação superior de jornalismo deve excluir os interesses estritamente corporativos e deve ser feita, nos termos realizados até aqui, na perspetiva do interesse público e da qualidade da informação. A complexidade e as responsabilidades sociais exigidas a estas funções não podem estar apenas dependentes de aspetos vocacionais como a criatividade- a sensibilidade e a agilidade, nem ao domínio das ferramentas básicas do passado. Na época em que os cidadãos cometem atos cívicos de jornalismo, o jornalismo tem de estar mais além. Como refere Miranda (2008: 42-43), no novo ambiente tecnológico do jornalismo o manejo de ferramentas mais ou menos sofisticadas, é apenas uma parte da "formação humanística do informador", "implicando também aqui competências culturais, comunicacionais e jornalísticas" (Mesquita, 2003: 191-192).

Efetivamente, o jornalismo continua a necessitar de um conjunto de competências culturais e transversais (História, Direito, Ciências Políticas, Ética, Literatura, Sociologia, Economia, Línguas...) já assim identificadas por Pulitzer ([1904] 2011, p. 44), no início do século XX, cujos conteúdos carecem ser adaptados à formação de jornalistas. 
No entanto, quando se fala no perfil humanista da formação do jornalista, negligencia-se frequentemente a componente das Ciências da Comunicação e o seu lugar próprio no jornalismo. Hoje, não é sustentável a expressão de Wilbur Schramm para quem a comunicação era apenas "uma disciplina de cruzamento, onde são muitos os que por lá passam, mas poucos os que se detêm" (citado por Lazar, 1996, p. 3). As Ciências da Comunicação geraram um acervo de estudos nas suas diferentes áreas de estudo, que constituem um saber incontornável para 0 exercício responsável da profissão.

A estes saberes junta-se ainda uma componente técnica e tecnológica cada vez mais exigente, não só associada às narrativas - tais como competências de escrita, vídeo, som, blog's, podcast, fotografia (Scherer, 2011: 176) - como aos novos perfis de profissionais - editores de metadados, editores especializados em motores de busca, gestores de redes sociais, jornalistas visuais, agregadores de conteúdos, produtores Web (Scherer, 2011: 174). Nestas condições, não se vê outra forma de compaginar tantas exigências de formação que não seja por cursos superiores, não limitada a uma formação pós-graduada. Limitar a formação a esse âmbito representa continuar a insistir na redução do jornalista a competências meramente técnicas, priorizando os interesses utilitários corporativos dos media de recrutamento barato de recursos humanos, em detrimento da componente crítica e intelectual (Coelho, 2014, p. 262-275).

\section{Mercado dos media e desprofissionalizaÇão}

Apesar de reconhecer que a abertura do jornalismo permitiu à profissão adaptar-se às alterações que sofreu desde a segunda metade do século XX, Gérard Cornu e Denis Ruellan salientam que essa estratégia incorre no risco de conduzir à própria "dissolução" da profissão. A alternativa a essa dissolução poderá passar, agora, pela necessidade de se proceder a uma nova delimitação do território do campo profissional, a exemplo do que os jornalistas franceses levaram a cabo nos anos 30 do século XX, nomeadamente, afastando do centro da produção jornalística os "políticos", os "professores", os "amadores" e os "aproveitadores" e excluindo as práticas narrativas literárias do seu campo (Cornu \& Ruellan, 1993, 155-156).

As NTIC estão novamente a promover esta fluidez socioprofissional, esbatendo as fronteiras narrativas, por um lado, e socioprofissionais, por outro. Novos conceitos propõem uma mistura do jornalismo, dissolvendo-o no imenso mar da comunicação, tais como: produsers (mistura entre utilizadores e produtores da informação), publireportagens (miscigenação entre o discurso jornalístico e a estratégia publicitária), infoentertenimento (conteúdos de informação e entretenimento), native advertising, corporate Journalism ou brand Journalism que, mais do que jornalismo, é um boundary work (Fidalgo, 2017). Estas expressões refletem a atualidade de formas crescentes de mestiçagem de tarefas, de narrativas, de novas funções normativas e de perfis profissionais híbridos, acelerando a banalização do jornalismo e a sua desprofissionalização (Camponez 2011). A origem destas transformações, se tem sido determinada pelas NTIC, também não o tem sido menos pelas empresas de media e os modelos económicos comerciais, colocando 0 êthos jornalístico sob forte pressão: 
“Neste contexto, os jornalistas atravessam mutações socioprofissionais complexas. A Tendência é a da polivalência de funções em nome de um trabalho mais cooperativo, descentralizado, infográfico, à distância ou com recurso constante aos jornalistas freelance, em sistema de outsourcing, trabalho precário. 0 capitalismo digital pretende um jornalismo do tipo colaborativo, de fronteiras híbridas entre os diferentes sectores de atividade. Em princípio, a autonomia jornalística lidaria mal com a pressão dos gestores pela imposição dos valores de mercado no seu trabaIho, mas estão a ocorrer mudanças no quadro mental do jornalista" (Garcia \& Meireles, 2017, p. 166).

Neste quadro, os jornalistas confrontam-se com a exigência ética de repensarem os seus fundamentos normativos e a forma de exercício da profissão. A nosso ver, isso passa por um reforço do jornalismo orientado para a democracia, em detrimento do mercado, do reconhecimento dos saberes e da formação fundamentais. Implica, por consequência, estruturas e formas de organização também mais fortes e capazes de responderem aos crescentes desafios éticos da autorregulação e da accountability.

\section{CONCLUSÃo:}

A proposta de fechamento da profissão de jornalista resulta do reconhecimento das potencialidades que as NTIC trouxeram para o espaço público, nomeadamente no campo da liberdade de expressão, de produção e de difusão de ideias. Como salienta Meyer, os valores do jornalismo foram forjados num contexto de raridade da informação (Meyer, 1996, pp. 10-11), pelo que hoje urge, em nosso entender, repensar os valores, as competências e as especificidades da função social do jornalista, num quadro de abundância e em que os jornalistas deixaram de ter um papel fundamental em fazer chegar a informação ao público. 0 fechamento do acesso à profissão não significa o fechamento do jornalismo à sociedade. Falamos de um trabalho de reconstrução da profissão que implica que seja complementado com novas formas de organização e de regulação da profissão de que os jornalistas devem ser os primeiros mentores. 0 desafio visa evitar a diluição do jornalismo, confrontado que está por visíveis processos de desprofissionalização, de mercadorização dos seus conteúdos e de banalização das suas competências. Essa redefinição tem como pressuposto que as democracias continuarão a precisar de um jornalismo capaz de manter cidadãos bem informados e visões críticas e olhares escrutinadores (Ulla, 2016, p. 27). Sem esse pressuposto toda a discussão aqui iniciada é uma pura perda de tempo

\section{ReferênCias Bibliográficas}

Allcott, H. \& Gentzkow M. (May, 2017). Social Media and Fake News in the 2016 Election. Retrieved from https://nyuscholars.nyu.edu/en/publications/social-media-and-fakenews-in-the-2016-election.

Ash, G. T. (2017). Liberdade de Expressão - Dez princípios para um mundo interligado. Lisboa: Temas e Debates. 
Bastos, H. (2011). Ciberjornalistas em Portugal - Práticas, papéis e ética. Lisboa: Livros Horizonte.

Bernier, M.-F. (1994). Éthique et Déontologie du Journalisme. Sainte-Foy: Presses Universitaires de Laval.

Bertrand, C.-J. (1997). La Déontologie des Médias. Paris: Presses Universitaires de France.

Bulmer, M. \& Bell, J. (January, 1985). The press and personal privacy - Has it gone too far? The Political Quarytely, 56 (1), 5-22.

Castells, M. (2008). The new public sphere: global civil society, communication networks, and global governance. ANNALS - AAPSS, 616, 78-93. doi:10.1177/0002716207311877.

Castells, M. (2009). Communication Power. Oxford, New York: Oxford University Press.

Charron, J. \& De Bonville, J. (2004). Le Journalisme et le marché : de la concurrence à I'hiperconcorrence. In Colette Brin, J. Charron \& J Bonville, Nature et Transformation du Journalisme - Théorie et recherches empiriques(273-316). Québec: Les Presses Universitaires de Laval.

Coelho, P. (2014). A Formação Académica para o Jornalismo do Século XXI: Sobre Questões de Prática e Técnica. Jornalismo e mercado - os novos desafios colocados à formação. Tese de doutoramento em Ciências da Comunicação, Estudo dos Media e do Jornalismo, UNL, março. Retirado de https://run.unl.pt/bitstream/10362/12109/1/Tese\%20PC.pdf.

Cornu, G. \& Ruellan, D (1993). Technicité intellectuelle et professionnalisme des journalists. Réseaux, 11 (62), 145-157.

Dahlgren, P. (2011). Media and Political Engagement - Citizens, communication, and democracy. Cambridge, New York, Melbourne, Madrid, Singapore, São Paulo, Tokyo, Mexico City: Cambridge University Press.

Dahlgren, P. (2014). Social media and political participation: Discourse and deflection. In C. Fuchs \& M. Sandoval (eds.), Critique, Social Media and the Information Society (191202). Nova lorque: Routledge.

Delporte, C. (2016). 0 ensino do jornalismo no século XXI. Mediapolis - Revista de Comunicação Jornalismo e Espaço Público, 3, 13-25.

Deuze, M. (2005). What is journalism? Professional identity and ideology of journalists reconsidered. Journalism 6 (4), 442-464. DOI: 10.1177/1464884905056815

Deuze, M. (2017). No one listens when everyone speaks: on the future of media in media life. In Mediapolis - Revista de comunicação jornalismo e espaço público, 4, 11-37. DOI: 10.14195/2183-6019_4_1

Dourado, M. (2009). A Esfera Pública no Jornalismo Cidadão Online: Refletindo a reconfiguração do conceito de Habermas nas práticas colaborativas da notícia. Retirado de http:// www.bocc.ubi.pt/pag/bocc-jornalismo-mariana.pdf.

Edström, M., Kenyon, A. \& Svensson, E.-M. (eds) (2016). Blurring the Lines - Market-driven and democracy-driven freedom of expression (pp. 29-39). Göteborg: Nordicom.

Eveno, P. (2010). Les Grands Articles Qui Ont Fait L'Histoire. Paris: Flammarion.

Fenton, N. (2012). The internet and social networking. In J. Curran, N. Fenton \& D. Freedman (eds.), Misunderstanding the Internet (123-148). Oxfordshire: Routledge.

Ferreira, G. B. (2011). Democracia digital e participação política: 0 acesso e a igualdade na deliberação online. Media \& Jornalismo (Digital Divides/Fracturas Digitais), nº $18,46-61$. 
Garcia, J.L. \& Meireles, S. (2017). Jornalismo sob a ameça da tecno-mercantilização da informação. In José Nino Matos, Carla Baptista e Filipa Subtil (orgs.), A Crise do Jornalismo em Portugal (169-178). Lisboa: Deriva, Le Monde Diplomatique.

Giroux, G. (1991). La Déontologie professionnelle dans le champ du journalisme - Portée et limites. Comunication, 12 (2), 117-134.

Habermas, J. ([1962] 2013). A Transformação Estrutural da Esfera Pública - Investigações sobre uma categoria da sociedade burguesa. Lisboa: Fundação Calouste Gulbenkian.

Jeanneney, J.-N. (1996). Uma História da Comunicação Social - Lisboa: Terramar.

Keane, J. (2013). Democracy and Media Decadence. Nova Iorque: Cambridge University Press.

Kenyon, A. (2016). Who, what, why an how - Questions for positive free speech an media systems. In M. Edström, A. Kenyon \& E.-M. Svensson (eds), Blurring the Lines - Market-driven and democracy-driven freedom of expression (29-39). Göteborg: Nordicom.

Kovach, B. \& Rosenstiel, T. (2005). Os Elementos do Jornalismo: 0 que os profissionais de jornalismo devem saber e o público deve exigir. Porto: Porto Editora, 2005.

Kumar, K. (1995). Da Sociedade Pós-Industrial à Pós-Moderna - Novas teorias sobre o mundo contemporâneo. Rio de Janeiro: Jorge Zahar.

Lambeth, E. B. (1992). Comitted Journalism - An ethic for the profession, Bloomington, Indianapolis, Indiana Univerity Press.

Mcbride, K. \& Rosenstiel, T. (eds). (2014). The New Ethics of Journalism: Principles for the 21st Century. Londres: Sage Publications.

Mesquita, M. (2003). 0 Quarto Equívoco - O poder dos media na sociedade contemporânea. Coimbra: Minerva Coimbra.

Miranda, J. M. G. (2008). El Periodismo en el Siglo XXI - Uma profesión en crisis ante la digitalización. Madrid: Universidade Rey Juan Carlos e Dykinson.

Montalbán, M. V. (1997). Historia y Comunicación Social - Edición revisada y ampliada. Barcelona: Crítica.

Peixinho, A. T. (2016). 0 contributo das humanidades para o ensino do jornalismo. Mediapolis - Revista de Comunicação Jornalismo e Espaço Público, 4, 105-117.

Pissarra, J. Ética da comunicação, media e linguagem. In A. T. Peixinho, C. Camponez, I. Vargues. J. Figueira (orgs), 20 Anos de Jornalismo Contra a Indiferença (120-143). Coimbra: Imprensa da universidade de Coimbra

Powell, W., Jempson; M. (2014). More accountability in the digital age? The influence of new technologies. In S. Fengler, T. Eberwein, G. Mazzoleni, C. Porlezza \& St. Russ-Mohl, Journalists and Media Accountability - An international study of news people in the digital age(115-128). New York, Washington D.C./Baltimor, Bern, Frankfurt, Berlin Brussels, Vienna, Oxford: Peter Lang.

Pulitzer. J. ([1904] 2011). Sur le Journalisme - Essai. S/I.: Circé.

Ruellan, D. (1997). Les "Pro" du Journalisme - De l'état au statut, la construction d'un espace professionnel. Rennes: Presses Universitaires de Rennes.

Ruellan, D. (2010). La déontologie des journalistes, un discours identitaire. Texte présenté au colloque Les journalismes: réalités plurielles, éthique commune? Université d'Ottawa. Retrieved from http://www.crej.ca/REJ2010/Ruellan.pdf. 
Scherer, É. (2011). A-t-on Encore Besoin des Journalistes?- Manifeste pour un "journalisme augmenté". Paris: PUF.

Schudson, M. (2010). Descobrindo a Notícia - Uma história social dos jornais nos Estados Unidos. Petropólis: Vozes.

Sennett, R. (2006). La Cultura del Nuevo Capitalismo. Barcelona, Editorial Anagrama.

Serje, J., Kahn, J.-F. \& Plenel, E. (2009). Faut-il Croire les Journalistes? Paris: Mordicus.

Solosky, J. (1993). 0 jornalismo e o profissionalismo»: alguns constrangimentos no trabalho jornalístico. In N. Traquina (org.), Jornalismo: Questões, Teorias e "Estórias" (91-100). Lisboa: Veja.

Splichal, S. \& Sparks, C. (1994). Journalists for the 21 Century. New Jersey: Aplex Publishing Corporation.

Splichal, S.(2002). Principles of Publicity and Press Freedom. Lanham, Boulder, New York, Oxford: Rowman \& Littlefield Publishers.

Stearns, J. (2013). Acts of Journalism: defining press freedom in the digital age. New York: Free Press. Retrieved from https://www.freepress.net/sites/default/files/resources/ Acts_of_Journalism_October_2013.pdf.

Ulla, C. (2016). Opening speech: Freedom os expression in transition. A media perspetive. In M. Edström, A. Kenyon \& E.-M. Svensson (eds), Blurring the lines - Market-drivem and democracy-driven Freedom of Expression (pp. 19-26). Göteborg: Nordicom.

Ward, S. (2004). The Invention of Journalism Ethics - The path to objectivity and beyond. London: McGill-Queen's University Press.

Ward, S. (2011). Ethics and the Media - An Introduction. Cambridge, New York, Melbourne, Madrid, Cape Town, Singapore, São Paulo, Delhi, Tokyo, Mexico City: Cambridge University Press.

Ward, S. (2015). Radical Media Ethics - A global approach. Malden, Oxford, West Sussex: Wiley Blackwell.

Ward, S. (2013). Why we need radical change for media ethics, not a return to basics. In Media Shift. Retirado de http://mediashift.org/2013/08/why-we-need-radical-change-for-media-ethics-not-a-return-to-basics/.

Ward, M. (2007). Jornalismo Online. São Paulo; Roca.

Wolf, M. (1987) Teorias da Comunicação. Lisboa: Presença.

Carlos Camponez - Professor auxiliar da Faculdade de Letras da Universidade de Coimbra. Jornalista freelancer, coordena o Grupo de Investigação em Comunicação Jornalismo e Espaço Público (GiCJEP), do Centro de Estudos Interdisciplinares do Século XX (CEIS20). 